\title{
Recovery of feline with Pectus Excavatum
}

\author{
Leticia Simas da Silva Cupertino ; Denise de Mello Bobány²; Marcelline Santos \\ Luz $^{2}$; Priscila Tucunduva ${ }^{2}$ \\ ${ }^{1}$ Veterinary practicioner \\ ${ }^{2}$ Unifeso-Centro Educacional Serra dos Órgãos - Teresópolis- Rio de Janeiro-Brasil
}

\begin{abstract}
Pectus Excavatum is a rare congenital deformity of the sternum, of unknown cause, which may involve genetic, and which generates dorsoventral narrowing of the thoracic cavity. Cats are more affected than dogs and the abnormal position of the heart in the thorax can lead to heart murmur and compromise of venous return, dyspnea being the most common clinical sign. The clinical diagnosis is made through physical examination and palpation, confirmed by thoracic X-ray. Often, due to lack of clarification from the owner about the problem, many newborn dogs and cats are abandoned or euthanized without a thorough evaluation of their clinical status and possible treatments. The objective of this study was to report the case of a feline, male, with no defined breed, found in the street, aged 30 days, attended at the Clinic School of Veterinary Medicine of UNIFESO with clinical signs of mild dyspnea, exercise intolerance, and deformity in the thoracic cavity suggestive of Pectus Excavatum. The clinical suspicion was confirmed with the chest X-ray. Due to the fact that the cat was slightly affected, surgical correction was not indicated, and only postural procedures were recommended. Pectus Excavatum is an important malformation that can be serious, but when diagnosed early there is a great chance of treatment and recovery of the animal

Keywords: Carved Chest, thoracic deformity, cat.
\end{abstract}

\section{Introduction}

The excavated chest or Pectus Excavatum is an unusual congenital anomaly of the sternum and costochondral cartilage that affects dogs and cats, with the most affected cats [1-3]. Be diagnosed soon after birth or a few days later [4]. In addition to dogs and cats, this malformation has been described in humans, primates, lemurs (Lemur variegatus) and in nutria (Mycastor coypus) [2,5].

In veterinary medicine, diseases of a rare character, until now little known, are increasingly being diagnosed and, due to the potential for heritability, it is recommended that animals with Pectus Excavatum be castrated, although the deformity is usually congenital [6], which is based on the results obtained in the literature. There is still insufficient data to prove the racial or sexual predisposition to Pectus Excavatum malformation in dogs and cats [1].

Pectus Excavatum is characterized by funnel-shaped cavitation [2,7] and frequently affected animals are asymptomatic and may present progressive cardiovascular and / or respiratory After birth leading owners to seek a veterinarian more quickly $[1,3,7,8]$. These signs are related to the severity of the disease and include dyspnoea, exercise intolerance, recurrent pneumonia and respiratory changes. The abnormal position that the heart can stay in the chest can lead to a cardiac murmur and loss of venous return, signals that are more frequently observed by the owner $[1,6]$. In more severe cases growth retardation and vomiting are observed $[3,5]$.

The diagnosis of Pectus Excavatum can be made, in most cases, clinically because the sternal defect is usually palpable [1,9]. Another method of diagnosis is radiography, which is performed in the laterolateral position, thus demonstrating a reduction of thoracic volume and elevation of the sternum in the caudal thorax. The cardiac position is usually altered, with the heart deviated to the left of the midline [1], in some cases it may be displaced to the right side and can be observed in the X-ray in the ventrodorsal position [6]. The radiographs help to determine other abnormalities, such as tracheal hypoplasia, cardiac abnormalities and pneumonia [9]. In Pectus Excavatum, when the diagnosis is made early, the animal has a high chance of survival and can usually be treated clinically, similar to what is done in human medicine in patients with small deformities [10]. Therefore, the clinical treatment of Pectus Excavatum may be only conservative [3]. Young animals with mild deformity of the sternum can achieve a very close conformation of the normal without surgical necessity [1]. Veterinarians will advise owners to perform mild mediolateral compressions on the animals' thorax in order to increase respiratory pressure and thus push the sternum forward, being this procedure more common in young animals $[1,3,9]$.

Because Pectus Excavatum is a congenital malformation that is still very unknown and rare, however, with an excellent perspective of cure with a clinical treatment, when the animals are young, it becomes interesting to know more and more the subject because, the lack of Clarification about malformation causes 
many owners to abandon or even perform euthanasia on their animals without a thorough evaluation of their clinical status and the possibilities of treatment and maintenance of life and well-being.

The objective of this study was to report the case of a newborn feline with clinical signs of Pectus Excavatum that was recovered without using splints, vests or surgical necessity.

\section{Case Report}

A feline, male, with no defined breed found on the street and weighing 300 grams was taken to the Clinic School of Veterinary Medicine of UNIFESO on November 17, 2014 with a history of dyspnea and exercise intolerance (Figure 1). The owner reported that the animal was joking when it suddenly presented respiratory difficulty and stopped the physical activity.

At clinical examination, the main symptoms observed were mild dyspnea, exercise intolerance, and depression in the caudal part of the sternum suggestive of Pectus Excavatum. The clinical suspicion was confirmed with thoracic X-rays (Figures 2 and 3), where a sternum depression was evidenced.

As the feline of the case was slightly affected, presenting discreet respiratory symptoms, no surgical correction was indicated. The veterinarian advised the owner to leave the animal in the ventral position, preventing it from being supine. In this way, the weight of the thoracic viscera on the sternum could return the structure normal, since the cat was still very young. During two years of follow-up, the animal presented a normal development, returning to vaccinations and revisions to evaluate the malformation, where the satisfactory evolution of the feline was observed clinically (Figure 4). After two years, the thoracic X-ray was taken in order to verify if there was still malformation (Figures 5 and 6).

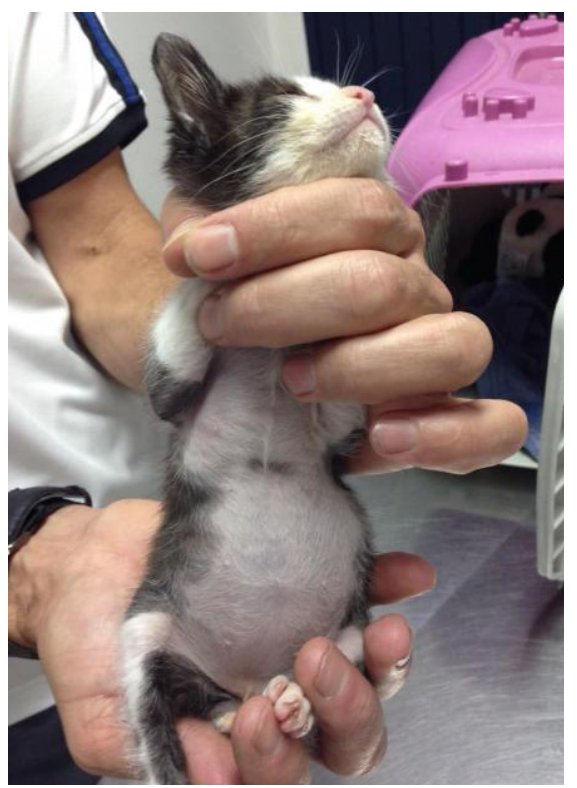

Figure 1 - Feline of this report on the day of care, presenting depression in the caudal part of the sternum

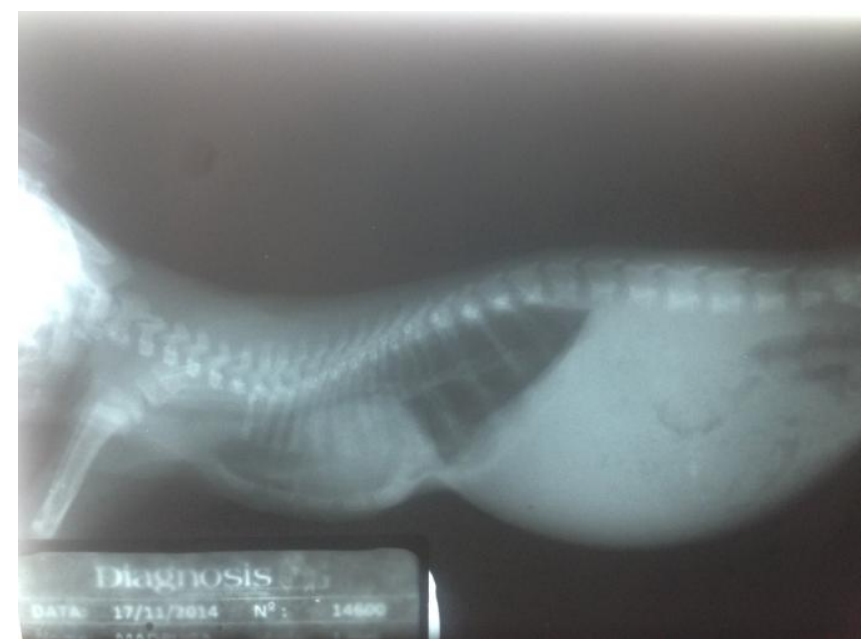

Figure 2 - X-ray confirming the clinical suspicion of Pectus Excavatum (arrow) 


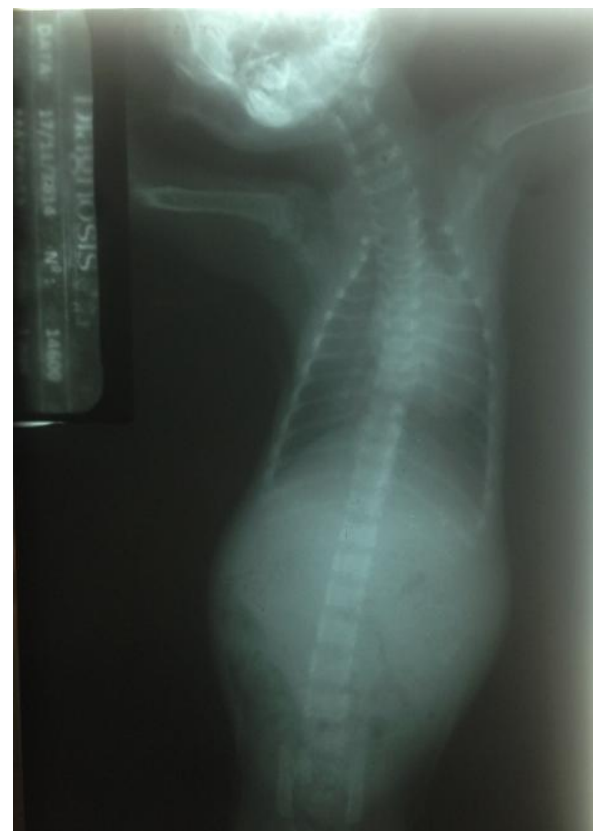

Figure 3 - X-rays in the ventrodorsal projection, showing the displacement of the cardiac silhouette to the left

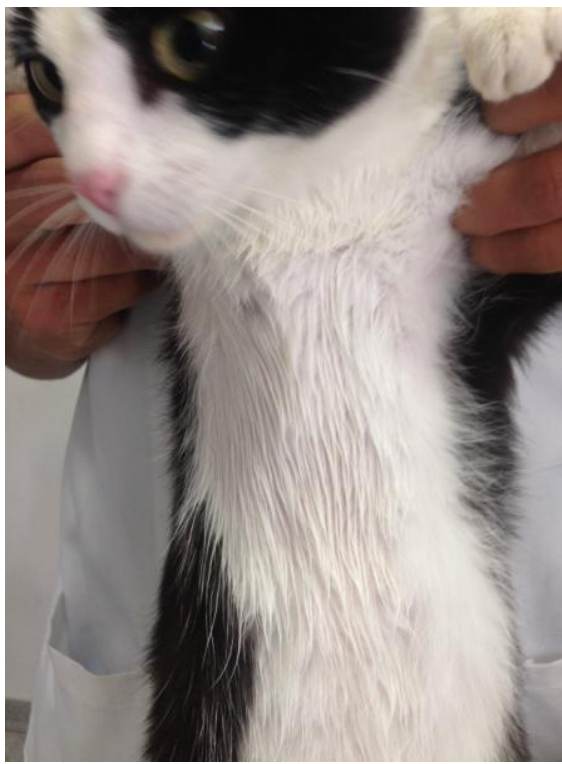

Figure 4 - Feline of this report after 2 years, with normal development

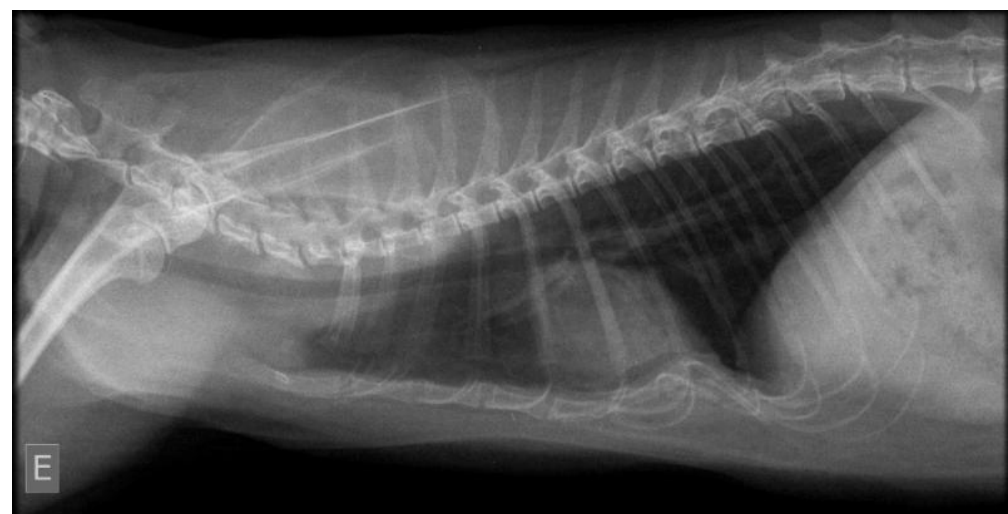

Figure 5 - Thoracic X-ray in the laterolateral projection of the feline after 2 years, showing a slight alteration in the sternum, without cardiac and respiratory complications 


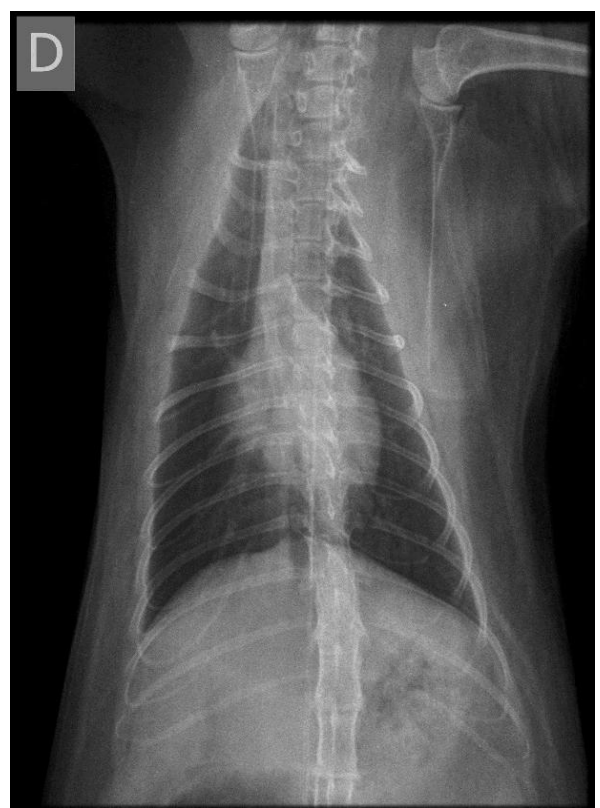

Figure 6- Thoracic x-ray in the ventrodorsal projection of the feline after 2 years, showing the normal position of the heart

\section{Discussion}

The feline of the present report fits the statistics presented by Fossum, Boudrieau and Hobson [11], who reported that male cats were most affected.

The signs of exercise intolerance and dyspnea presented by the animal in the reported case coincide with the statements of Miranda et al. [3], Sánchez et al. [5] and Rahal et al. [6].

As described by Díaz and Aguirre [12], the owners of the cat in this report had not repaired a possible malformation of the sternum, since the animal was asymptomatic at first, but they only sought veterinary medical assistance when the sternum presented symptoms of dyspnea and Exercise intolerance.

The animal of this study presented the X-ray in the ventrodorsal position, the heart deviated to the left of the midline, agreeing with Grace [1], Miranda et al. [3] and Rahal et al. [6].

In the present report, due to the age of the animal and the degree of severity of the malformation, conservative treatment was chosen, agreeing with Grace [1], Miranda et al. [3] and Fossum [9], and according to Crigel and Moissonnier [8] who state that pups are more likely to recover.

The cat in this report was slightly affected and the recommended treatment followed the conservative line as recommended by Grace [1], Miranda et al. [3] and Fossum [9] and, as the authors stated, the commitment and collaboration of the owners are extremely important for the success of this therapy.

\section{Final Considerations}

The present study shows the importance of orientation to the owners, by the veterinarians, about the possibility of clinical recovery of the animals slightly affected, evaluating the severity of the malformation mainly when the animals are still young.

With correct conservative treatment, the animal had a chance to lead a normal life without surgery

\section{References}

[1]. S.F. Grace, Peito Escavado (Pectus Excavatum), in G. D. Norsworthy, M. A. Crystal, S. F. Grace, , L. P. Tilley, O Paciente Felino (São Paulo: Roca, 2009) 249-250.

[2]. R.F.S. Molano, F.J.P. Ordónez and I.C.S. Gallego, Descripción de un caso de la malformación congénita Pectus Excavatum en un felino doméstico, Revista lasallista de investigación,, 7(2), 2010, 124-131.

[3]. F.G. Miranda, J.O. Sena, L.C. Pereira, S.C. Azevedo, M.S. Oliveira, A.C. Nepomuceno, C.M.F. Rezende, R.C.S. Torres, Abordagem diagnóstica e terapêutica de Pectus Excavatum em gata- relato de caso, Clínica veterinária, XX(118), 2015, 84-92.

[4]. H.H. Grenn, D.E. Lindo, Case report. Pectus Excavatum (Funnel Chest) in a feline. Canadian Veterinary Journal, 9(12), 1968, 279282.

[5]. A.G. Sánchez, M.M. Martinez, T.S. Oviedo, N.P. Pastrana, Pectus Excavatum associado a ectopia cordis en un neonato bovino. MVZ-Córdoba, 10(2), 2005, 684-688.

[6]. S.C. Rahal, M.M. Morishin Filho, E. Hatschbach, V.M.V. Machado, K.P. Aptekmann, A.P. Corrêa, Pectus Excavatum in two littermate dogs. Canadian Veterinary Journal, 49(9), 2008, 880-884.

[7]. H.Y. Yoon, F. Mann, S.W. Jeong, Surgical correction of Pectus Excavatum in two cats. Journal of Veterinary Science, 9(3), 2008, 335-337. 
[8]. H.M. Crigel, P. Moissonnier, Pectus Excavatum surgically repaired using sternum realignment and splint techniques in a young cat. Journal of Small Animal Practice, 49(7), 2005, 352-356.

[9]. T.W. Fossum, Cirurgia de pequenos animais, 4 (Rio de janeiro: Elsevier, 2014)

[10]. M.S. Coelho, P.S.F. Guimarães, Pectus Excavatum: abordagem terapêutica. Revista do Colégio Brasileiro de Cirurgiões, 34(6), 2007, 412-427.

[11]. T.W. Fossum, R.J. Boudrieau, P. H. Hobson, Pectus Excavatum in eigth dogs and six cats. Journal of the American animal hospital association, 25(5), 1989, 595-605.

[12]. V.M. Molina Díaz, J.C. Aguirre, Pectus Excavatum in an english bulldog: a case report. CES Medicina Veterinaria y Zootecnia, 7(2), 2012, 65-70 